\title{
Eficacia publicitaria en redes sociales: el caso de Mango en Facebook España
}

Carmen Llorente Barroso | carmen.Ilorentebarroso@ceu.es

Ángel Bartolomé Muñoz de Luna | abartolome@ceu.es

Esther Navarro Martínez | sther_ct@hotmail.com

Universidad CEU SAN PABlo de MAdRid

Resumen: Este trabajo analiza las redes sociales como nuevas plataformas publicitarias que se deben tener en cuenta a la hora de desarrollar el plan estratégico de una marca. Se ha hecho un estudio del panorama de las redes sociales, sus usos y percepciones, y su relación con las marcas y la publicidad. Para poner en práctica las oportunidades que ofrecen, se describe el modelo desarrollado por Mango en su página oficial de Facebook y se extrae un modelo de eficacia publicitaria en redes sociales a partir de los aprendizajes obtenidos.

Palabras clave: Redes sociales, eficacia publicitaria, Facebook, Mango.

Abstract: This research examines social media as new advertising platforms that must be taken into account when developing the strategic plan of a firm. There has been a landscape study of social media in Spain, their uses and perceptions, their relationship with Brands and advertising. To implement the opportunities, it is described the model developed by Mango in its official Facebook page. From results obtained is extracted a model of advertising effectiveness in social networks.

Key words: Social media, advertising effectiveness, Facebook, Mango. 


\section{Introducción}

En las sociedades actuales, las redes sociales se han establecido como un micromedio de tal importancia que puede ser decisivo en la eficacia publicitaria de un determinado anunciante.

Respecto a la conceptualización de red social existen grandes complicaciones. De acuerdo con Flores Vivar (2009: 73-81), la red social se fundamenta en la existencia misma de Internet, que puede entenderse como la red social por antonomasia. Partiendo de esta premisa, se puede considerar la existencia de tres tendencias conceptuales:

- Una de carácter técnico, que considera que las redes sociales dependen de un tipo de tecnología que las enmarca en la blogosfera (Flores Vivar, 2009: 73-81).

- Otra de carácter social, que define a las redes sociales como "un lugar de encuentro" (Flores Vivar, 2009: 74) en el que amigos y/o personas afines pueden comunicarse y compartir contenidos. Al respecto, Boyd y Ellison (2008: 210) señalaban la complejidad que manifiesta esta tendencia conceptual por la diversidad de culturas que emergen alrededor de las redes sociales.

- Otra de carácter profesional, que contempla el uso de las redes sociales como un instrumento de trabajo. En este sentido, Fernández Hermana (2008: 75) habla de ellas como espacios virtuales organizados, orientados al desarrollo de proyectos.

Probablemente, el rasgo conceptual más característico de la red social es la interactividad y el alto nivel de autoría que ésta facilita a sus usuarios, ya que les convierte en creadores y creativos. Sin embargo, en el contexto de la publicidad, este rasgo es un arma de doble filo, ya que, aunque estas plataformas ofrecen valiosa información sobre el consumidor y su entorno, la participación del usuario no es plenamente controlable. De hecho, el modelo de crecimiento de estas plataformas se basa en un proceso viral catalizado por esta interactividad que encuentra uno de sus pilares en la teoría de los seis grados de separación, que afirma que cualquier persona está conectada a otra por un máximo de otras seis personas conocidas (Gordon y Curlee, 2011).

Aunque no existe una clasificación específica que considere las redes sociales en función de unos atributos determinados, el Observatorio de Redes Sociales diferencia las redes sociales puras, de las redes sociales no puras (The Cocktail Analysis, febrero 2011). Las redes sociales puras son aquellas comunidades virtuales que surgen para compartir afinidades (como Facebook, Tuenti, Hi5, LinkedIn, Twitter, MySpace y Flickr), mientras que las redes sociales no puras son aquellas comunidades virtuales que fomentan formas de relación comunicativa más o menos inmediata, bien para permitir la interacción entre personas que comparten afinidades, pero que no se conocen en su vida no virtual (como ocurre con foros y blogs), bien para permitir la necesidad de una comunicación instantánea entre personas que 
se conocen en su vida offline, pero que no necesariamente comparten afinidades (Skype o Messenger) (The Cocktail Analysis, febrero 2011: 18).

Facebook es de todas las redes sociales la más notoria, la que cuenta con mayor número de usuarios en todo el mundo y una de las más atractivas para los anunciantes, por ser la que mayores posibilidades creativas ofrece (IAB Spain Research, noviembre 2010; The Cocktail Analysis, febrero 2011). Por este motivo, se está convirtiendo en una de las plataformas más atractivas para las marcas anunciantes y en un foco de interés para agencias publicitarias, profesionales e investigadores de este campo.

Facebook, que empezó siendo un proyecto de un estudiante, se ha convertido en la red social número uno, a la que se suman más de 500 millones de usuarios en todo el mundo (Vincosblog [Base de Datos: Alexa y Google Trends], diciembre 2010). En el panorama mundial, se trata de la red social con mayor penetración, alcanzando un $73 \%$ de media, con las excepciones de Holanda donde destaca Hyves con un $96 \%$ de penetración, Brasil donde Orkut alcanza un $98 \%$ de penetración y China donde MySpace, la red social más popular, sólo logra un 47\% de penetración (Insites Consulting, 2010: 10-11).

En el panorama nacional, el mejor esbozo sobre la evolución de las redes sociales lo presenta The Cocktail Analysis a través de las tres olas realizadas por su Observatorio de Redes Sociales (noviembre 2008, enero 2010 y febrero 2011). En su primera ola, motivada por el interés que agencias y anunciantes mostraban por las redes sociales puras, entonces un fenómeno emergente, se señala el potencial de mencionado micromedio (The Cocktail Analysis, noviembre 2008). En enero de 2010, los datos obtenidos por su segunda ola, muestran el espectacular crecimiento de comunidades como Facebook y Tuenti, considerándolas uno de los ejes vertebradores del consumo digital con gran capacidad para generar engagement (The Cocktail Analysis, enero 2010); esta etapa corresponde a la consolidación de las redes sociales como un medio con autonomía propia dentro de Internet, que tiene cierta importancia en la vida del usuario. En febrero de 2011, los resultados ofrecidos por su tercera ola, demuestran que el fenómeno inicial, ya consolidado, se complica, adquiriendo nuevas vías de desarrollo (The Cocktail Analysis, febrero 2011). Según los resultados de esta última ola, los usuarios perciben las redes como algo más que un mero espacio relacional y comienzan a utilizarlas con objetivos prácticos; en esta línea, las marcas pasan de la simple presencia en las redes sociales, al aprovechamiento de su funcionalidad (The Cocktail Analysis, febrero 2011: 10). Durante esta etapa, Facebook consigue el liderazgo indiscutible en el ámbito del social media nacional, quitando a Messenger el preciado lugar (The Cocktail Analysis, febrero 2011: 13-14).

Qualman (2011), al enumerar hasta 21 tendencias sobre la evolución de los medios sociales, considera que Facebook, Twitter y LinkedIn serán, por su fortaleza, las únicas redes que sobrevivirán, pero su previsión más importante es la que se refiere a la conversión de Facebook en el nuevo Google (Qualman, 2011). 
Así posicionada en el mercado mediático, Facebook se constituye como una red social a tener en cuenta para lograr un plan de comunicación publicitaria eficaz. Respecto a la publicidad en redes sociales, los más importantes informes determinan la existencia de un panorama favorable a la presencia de marcas en las redes sociales, al no detectarse ni un rechazo importante hacia la publicidad ni una sensación de presión o saturación (IAB Spain Research, noviembre 2010: 44). De hecho, para 1 de cada 3 usuarios, la publicidad, lejos de ser intrusiva, se percibe "interesante o divertida" (The Cocktail Analysis, enero 2010). Sin embargo, la proactividad del usuario a recibir y/o seleccionar mensajes publicitarios se conforma como indicador clave de la aceptación de tales mensajes en mencionados espacios (The Cocktail Analysis, enero 2010: 30).

Las marcas deben tener en cuenta que las redes sociales se han convertido en una importante fuente de información para el consumidor y en uno de los más potentes prescriptores; de hecho, la fuente en la que más confían los usuarios a la hora de buscar información en entornos digitales sobre un producto o una marca, son los comentarios en redes sociales de los amigos y conocidos, seguido de los comentarios de expertos en foros (The Cocktail Analysis, febrero 2011: 71). Por ello, las posibilidades que ofrecen estas plataformas pueden ser decisivas para la eficacia publicitaria de un determinado anunciante, al ofrecerle la posibilidad de generar un diálogo con su público objetivo y, de esta manera, la oportunidad de incrementar su notoriedad sin provocar saturación.

La eficacia publicitaria en las redes sociales resulta esencial para las marcas, de forma más definitiva, en momentos de crisis como el actual. En 2009, el 88\% de los anunciantes ya utilizaba los medios sociales (especialmente, Twitter, LinkedIn y Facebook) como medio publicitario de lanzamiento de negocio (Stelzner, marzo 2009). En ese momento, ya se estimaba la importancia de medir el efecto de las acciones publicitarias en redes sociales y, poco después, un estudio sobre la eficacia de las inserciones (Ad Impressions) en Facebook, realizado entre BrandLift ${ }^{1}$ y la propia red social, permitía comprender la importancia y utilidad de mencionado valor. El estudio, centrado en la publicidad en Facebook, recurría a los datos cuantificables que la plataforma de Nielsen asignaba a ciertos indicadores de la eficacia, como el recuerdo publicitario (Ad Recall), la notoriedad de marca (Brand Awareness) y la intención de compra (Purchase Intent) (Gibs y Bruich, abril 2010). Una de las peculiaridades que presentan las acciones publicitarias en Facebook es el uso que hacen del "me gusta" (antes "hazte fan") que, en este estudio, se identifica como una estrategia que permite a las marcas conseguir el engagement del consumidor, ya que convierte a la red social en uno de los más potentes earned media o medios ganados². Así, el "me gusta" que incorporan ciertas campañas en Facebook, conforma una motivación de compromiso, que

\footnotetext{
${ }^{1}$ Plataforma propiedad de Nielsen que ha analizado los datos de respuesta de más de 800.000 usuarios de Facebook a 125 campañas publicitarias desarrolladas por 70 anunciantes en esta red social (Gibs y Bruich, abril 2010).

${ }^{2}$ Los medios ganados son aquellos por los que el anunciante no paga, pero cuyo valor ha ganado gracias a los efectos virales de una acción comunicativa que los usuarios comparten. Son ganados porque son generados por terceros y benefician al anunciante en igual o mayor medida que los medios por los que paga (Gibs y Bruich, abril 2010).
} 
puede plantearse en tres formatos diferentes que posibilita esta plataforma (Gibs y Bruich, abril 2010): el formato estándar de un anuncio en la página principal de la red social, el formato estándar que incorpora contenido de carácter social y aparece en la página principal de la red social con otros anuncios, y el formato orgánico que se publica como novedad en los tablones de amigos del usuario, comprometiéndoles a familiarizarse, de alguna manera, con la publicidad de la marca anunciada.

\section{Gráfico 1. Principales tipos de formatos publicitarios en Facebook}

\section{1: Engagement Ad}

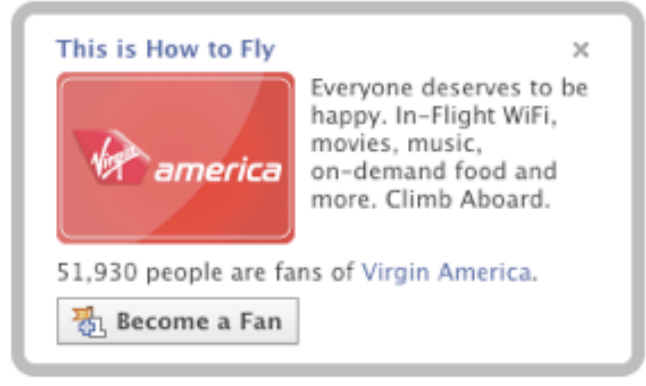

\section{3: Organic Ad Impression}

Alex Wu and Libby Leffler became fans of Virgin America

Faf 풍 about an hour ago - Become a Fan

\section{2: Ad with Social Context}

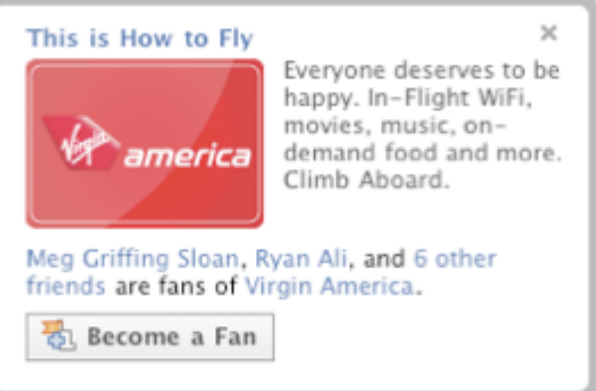

Fuente: Gibs y Bruich, abril 2010.

El formato estándar es más eficaz cuando aparece en la parte superior del conjunto de anuncios que se congregan en la página principal de la red social, garantizando un incremento de la notoriedad de marca y la intención de compra cuando la marca se anuncia en Facebook. Sin embargo, el formato orgánico es el que resulta más efectivo en términos de respuesta, ya que al utilizarlo, el recuerdo publicitario aumenta respecto a los otros formatos, logrando un nivel tres veces superior al formato estándar (Gibs y Bruich, abril 2010).

Todas estas consideraciones respecto a las nuevas tendencias comunicativas que plantean estas plataformas han empujado al desarrollo de esta modesta investigación focalizada en el caso concreto de Mango. Esta marca se posiciona entre una de las que mejor han aprovechado las posibilidades que brinda Facebook. Con más de un millón de fans en su página oficial de Facebook, cada día llama la atención de los usuarios con promociones a bajo coste que, en cambio, logran que la imagen de la marca esté mejor valorada en la red (Mango, 2011). Después del seguimiento de la publicidad de algunas marcas en la red, la capacidad de Mango para generar interactividad, respuesta y engagement, motivó el interés por conocer y trazar la estrategia publicitaria que siguen sus piezas en Facebook. Analizar sus características y determinar los recursos de Facebook empleados en su desarrollo, permite esbozar un modelo ideal de estrategia publicitaria en esta red social, que pueda orientar la construcción de anuncios publicitarios eficaces, a partir de las acciones de éxito 
desarrolladas por Mango. Esta es, precisamente, la pretensión de la investigación que se resume en este artículo.

\section{Diseño metodológico}

Para satisfacer los objetivos de este proyecto se diseñó una investigación que siguió el siguiente proceso:

a) En primer lugar, se llevó a cabo un estudio cuantitativo de medición de la eficacia de las piezas publicitarias utilizadas por Mango, durante los meses de marzo y abril de 2011, en su site oficial de Facebook. Este estudio permitió determinar la eficacia de las piezas según la cantidad de respuestas que obtenía.

b) En segundo lugar, se desarrolló un análisis cualitativo de la expresión y el contenido de estas piezas a partir de un modelo de aplicación y registro, previamente elaborado y sistemáticamente aplicado a cada pieza estudiada. Mediante este estudio cualitativo se descubren las características formales y conceptuales de las piezas, lo que permitirá extraer un modelo ideal de eficacia publicitaria en Facebook.

c) Por último, se realizó una entrevista a un experto de la comunicación publicitaria de la marca en redes sociales. Los conocimientos aportados por Carolina Ribalta, Coordinadora de Comunicación Online de Mango permitieron, en este caso, completar los resultados obtenidos mediante los dos métodos anteriores, y además, posibilitaron la concreción de ciertos aspectos inconclusos.

\section{Resultados}

\subsection{Resultados del estudio cuantitativo de medición de la eficacia de las piezas}

Esta metodología supuso tomar una serie de decisiones previas, entre las que destacan esencialmente dos:

- Se determinó que el número de respuestas positivas que debía alcanzar una pieza para ser considerada eficaz, desde el punto de vista comunicativo, tenía que ser, al menos, de más de un $50 \%$ del número total de respuestas obtenidas.

- Dentro de las respuestas positivas se diferenciaron dos posibilidades según el grado de actividad por parte del usuario que tales respuestas implicaban:

- El formato "me gusta" que facilita Facebook se consideró generador de respuestas positivas por lógica tautológica. Sin embargo, se determinó que el 
grado de implicación del usuario era, en este caso, inferior, dado que suponía un menor esfuerzo de participación por su parte.

- Los comentarios positivos que generaba cada pieza se consideraron una respuesta positiva más determinante y definitiva, al apreciarse un considerable mayor grado de participación por parte del usuario.

El estudio cuantitativo consistió en el análisis de las respuestas que obtuvieron las 57 impresiones publicitarias que aparecieron en la página oficial de Mango en Facebook, durante los meses de marzo y abril de 2011. Esto obligó a desarrollar un seguimiento exhaustivo de mencionado site en el periodo de análisis establecido.

En la siguiente tabla se presenta una parte extraída de la muestra real analizada y constituida por los ejemplos que han demostrado mayor eficacia comunicativa:

Tabla 1. Resultado de una parte ejemplar de la muestra analizada

\begin{tabular}{|c|c|c|c|c|}
\hline PIEZA & “ME GUSTA” & COMENTARIOS & $\begin{array}{c}\text { COMENTARIOS } \\
\text { POSITIVOS }\end{array}$ & $\begin{array}{c}\text { COMENTARIOS } \\
\text { NEGATIVOS }\end{array}$ \\
\hline $\begin{array}{c}\text { Fashion Show } \\
\text { Shangai }\end{array}$ & 2.677 & 78 & 78 & 0 \\
\hline $\begin{array}{c}\text { Gerard Piqué for } \\
\text { H.E }\end{array}$ & 1.859 & 235 & 235 & 2 \\
\hline $\begin{array}{c}\text { Mango in Vogue } \\
\text { París }\end{array}$ & 1.396 & 38 & 35 & 2 \\
\hline $\begin{array}{c}\text { Handbag Alexa } \\
\text { Fashion Show de } \\
\text { Moscú }\end{array}$ & 1.129 & 110 & 108 & 12 \\
\hline $\begin{array}{c}\text { Glamour Shopping } \\
\text { Night }\end{array}$ & 178 & 88 & 76 & 40 \\
\hline \begin{tabular}{c} 
TOTAL \\
\hline
\end{tabular} & $\mathbf{8 . 0 0 9}$ & $\mathbf{6 4 7}$ & $\mathbf{5 9 0}$ & $\mathbf{5 6}$ \\
\hline
\end{tabular}

Fuente: elaboración propia.

De esta manera, y teniendo en cuenta las consideraciones expresadas al inicio de este epígrafe sobre la eficacia de las piezas y los tipos de respuestas, se experimentaron las siguientes observaciones:

- La mayoría de las impresiones analizadas eran eficaces, ya que recibían un considerable porcentaje de respuestas positivas. De hecho, en todas las piezas analizadas, los comentarios negativos no superaron, en ningún caso, los comentarios positivos. Si bien, en algunas piezas, los comentarios positivos superaron, por poco, 
a los negativos. Esos comentarios negativos solían ser consecuencia:

- O bien de un error o fallo en el site.

- O bien de la viralidad generada en torno a la opinión negativa de un usuario respecto al uso de un producto de la marca. En este caso, las consecuencias alcanzan un mayor grado de gravedad y manifiestan un considerable carácter irreparable, ya que se trata de una opinión negativa fundamentada.

- Los fans de Mango manifestaron una actitud más activa ante el "me gusta" y una actitud más pasiva a escribir un comentario, por lo que el primer formato ("me gusta") genera más nivel de repuesta.

\subsection{Resultados del estudio cualitativo de expresión y contenido de las piezas}

Para llevar a cabo el análisis cualitativo se diseñó un modelo de registro analítico que especificaba, a modo de plantilla cerrada, las diferentes variables a estudiar.

\section{Gráfico 2. Modelo de aplicación y registro}

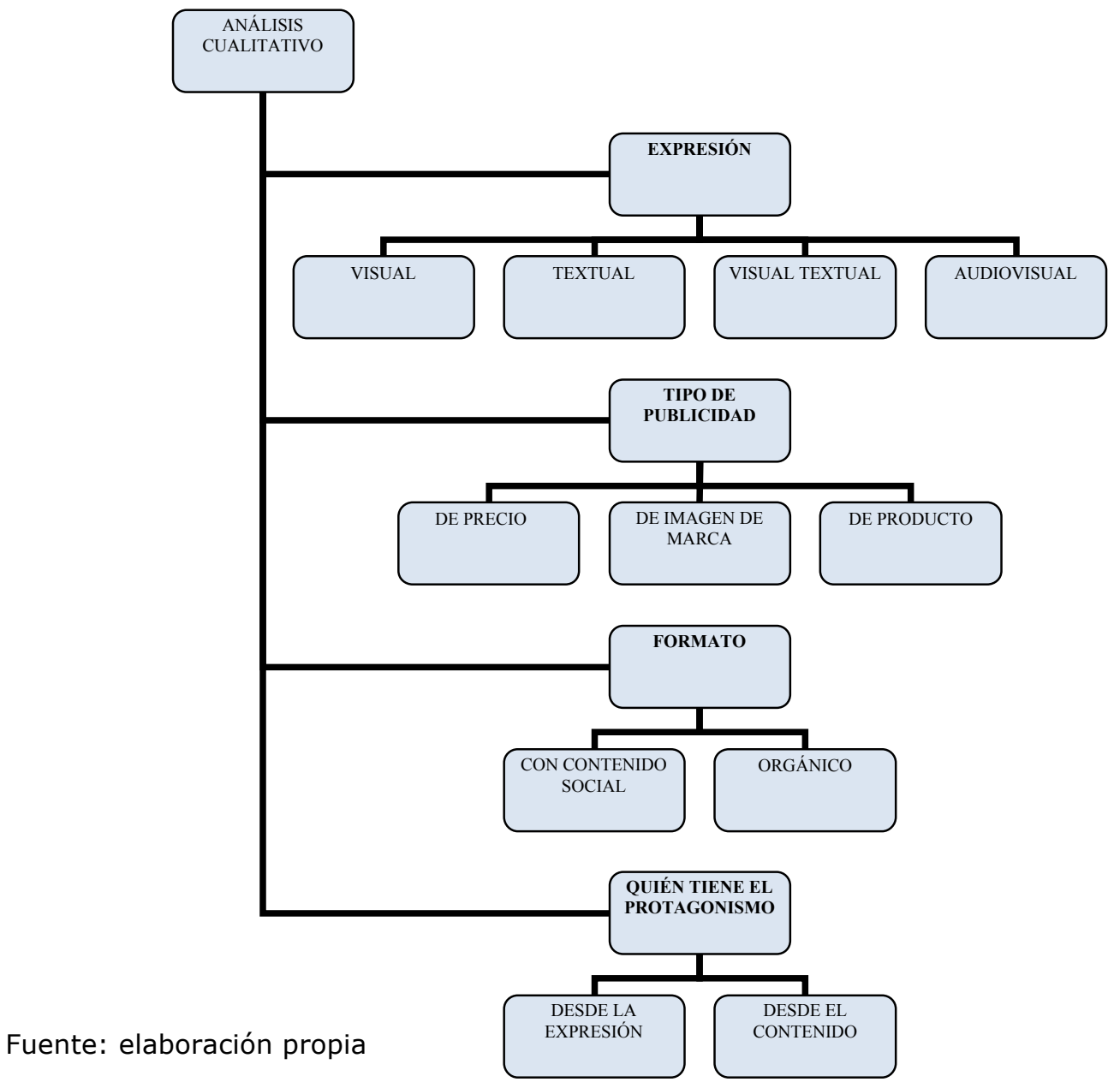


Así entendido, este modelo podía interpretarse como un plan de trabajo que orientó, organizó y estructuró el análisis de cada pieza de la muestra.

Este modelo se aplicó de forma sistemática a cada una de las piezas de la muestra escogida. De esta manera, se consiguió un registro analítico fiable, ya que, aunque esencialmente cualitativo, la aplicación sistemática del modelo permitió una acumulación ordenada y estructurada de datos, lo que posibilitó la extracción de inferencias de interés para los objetivos de esta investigación.

Los aspectos formales percibidos en la mayoría de las creatividades más eficaces, presentaban las siguientes peculiaridades:

- El predominio del lenguaje visual frente al textual.

- La apuesta por una publicidad fundamentalmente de producto, en la que se presentan los nuevos modelos de la colección (un 98\% de las piezas analizadas).

- Un mayor recurso al formato publicitario orgánico, que aparece en forma de notificaciones en el tablón de los usuarios.

- El recurso a famosos como coprotagonistas de las piezas. Se utiliza la imagen de los famosos para lograr una asociación de sus valores a los productos y la marca.

Así, los resultados obtenidos de tal aplicación sistemática, permitieron elaborar un modelo ideal de pieza publicitaria eficaz en Facebook, determinando que debe manifestar los siguientes rasgos:

a) Expresión: visual-textual, con mayor carga visual.

b) Tipo de publicidad: de producto, aunque siempre orientada a consolidar o mejorar el posicionamiento estratégico de la marca en su sector.

c) Formato: orgánico, propio de Facebook.

d) Protagonismo: un famoso acompañando a un producto de la marca o a la propia marca. 
Los gráficos 5 y 6 que se muestran a continuación presentan algunas de las piezas publicitarias más eficaces de la muestra analizada.

Gráfico 3. Pieza Shanghai Fashion Show. Ejemplo pieza eficaz de Mango en su site oficial de Facebook

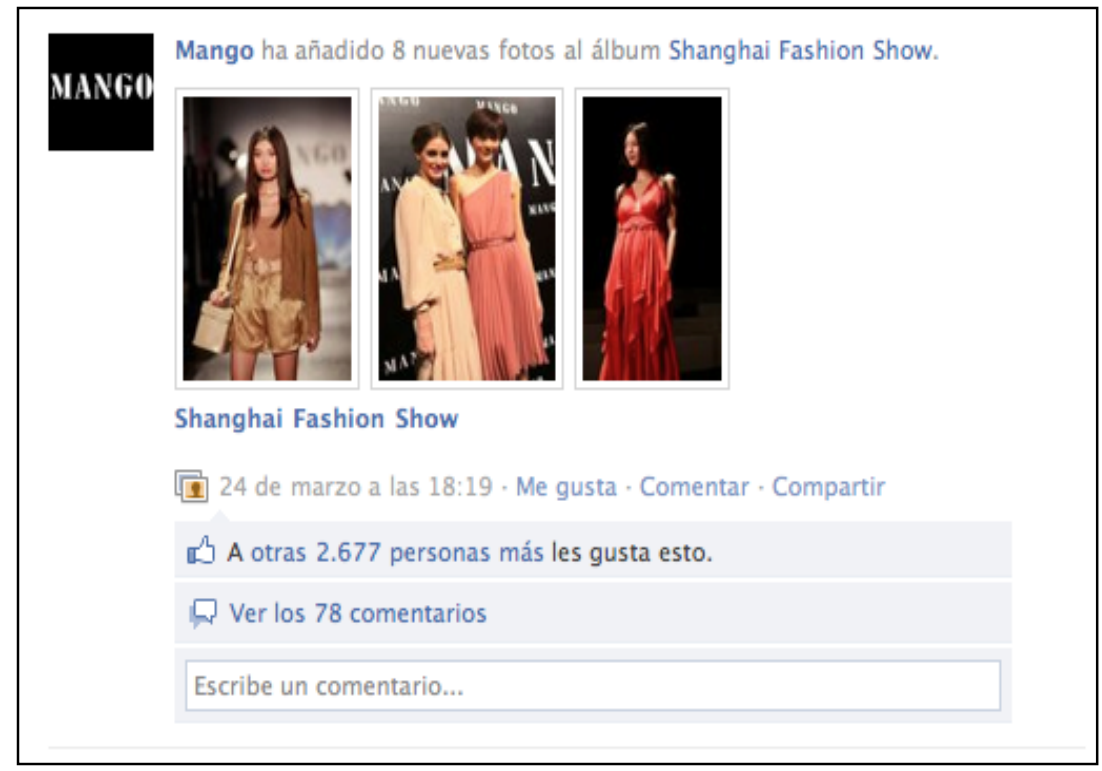

Fuente: site de Mango en Facebook (marzo-abril 2011).

Gráfico 4. Pieza Gerard Piqué for H.E. Ejemplo pieza eficaz de Mango en su site oficial de Facebook

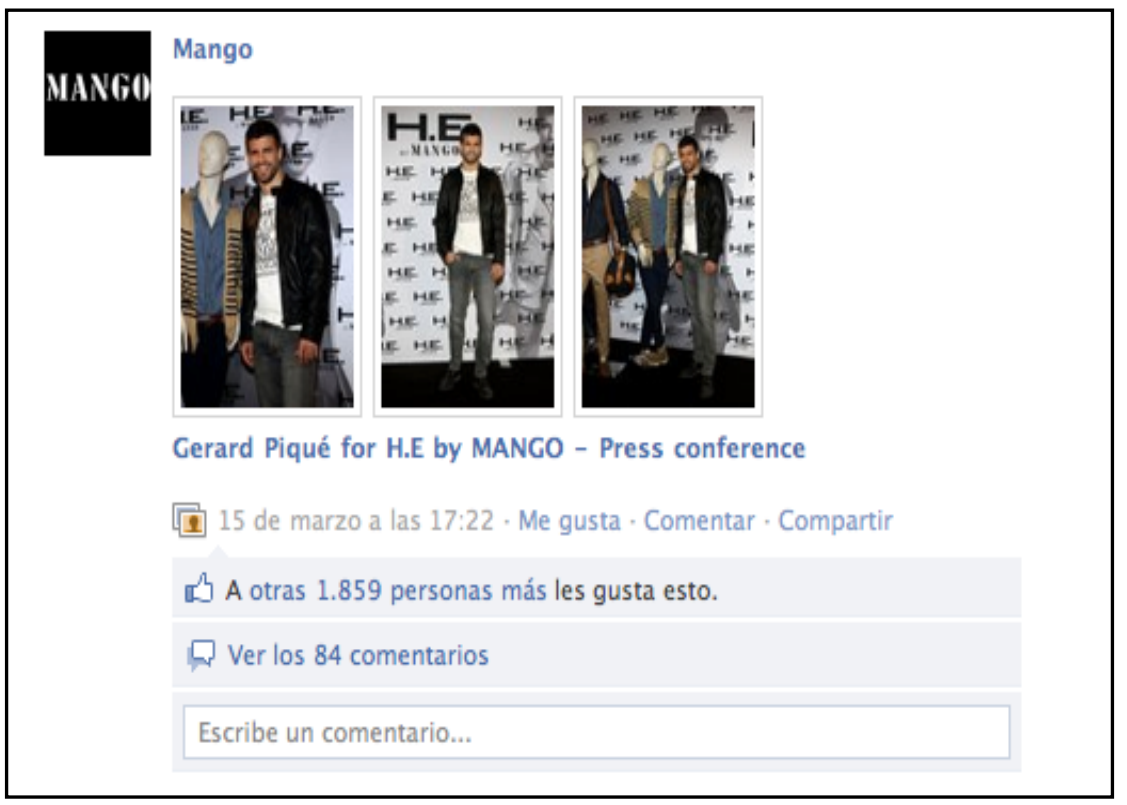

Fuente: site de Mango en Facebook (marzo-abril 2011).

Este modelo de eficacia publicitaria se fundamenta en: 
- La oferta de contenidos que, por un lado, incitan al usuario a dar una respuesta (más o menos inmediata), y por otro lado, generan el movimiento suficiente para atraer al resto de fans, es decir, aprovechan la viralidad de la red social.

- El cruce de usuarios y contenidos entre espacios digitales. Desde Facebook, Mango consigue orientar a sus fans, al site corporativo, al blog corporativo y a la página oficial de la marca, así como, a otras redes sociales como Twitter. De esta manera, se consigue aumentar el número de accesos a esos otros espacios, logrando que los contenidos tengan mucho dinamismo y que la presencia de la marca sea aún mayor y más notoria.

- El desarrollo de estrategias específicas que, adaptadas a las peculiaridades de la red, exploran creativamente los recursos y posibilidades de la plataforma para generar engagement. En este sentido, destaca el Emotion Ranking y la serie Qué Me Pongo By Mango, cuyas peculiaridades no permiten catalogarlos dentro de los formatos publicitarios habituales que ofrece Facebook (impresión estándar, impresión de tipo orgánico, impresión de contenido social):

- El Emotion Ranking facilita, en tiempo real, datos de los fans de todo el mundo. A modo de gráficos, ofrece porcentajes sobre el estado de ánimo de todos aquellos usuarios que han hecho click en los distintos estados, de manera que a cada estado de ánimo le corresponde un look diferente que lo identifica (Torres, 2010).

- La serie Qué Me Pongo By Mango, cuyas propias protagonistas hacían un llamamiento para que los fans se metieran en Facebook y votaran un look. De tal forma, que este look aparecería, más tarde, en un capítulo de la serie. Esta propuesta ha generado muchas respuestas por parte de los seguidores, contribuyendo con éxito a los propósitos publicitarios de la marca.

- La orientación de todas las acciones hacia un posicionamiento estratégico de la marca en su sector de competencia para la consecución de una imagen positiva. Todas las acciones en Facebook están destinadas a consolidar y/o mejorar la imagen de la marca, mediante la potenciación de la interactividad con los clientes-seguidores de dicha marca.

3.3. Resultados de la entrevista a un experto en la comunicación publicitaria de la marca en 
redes sociales

Los datos obtenidos del estudio cuantitativo y del análisis cualitativo, por un lado, pusieron de manifiesto la eficacia de las piezas de Mango en su página oficial de Facebook; y por otro lado, posibilitaron el diseño de un modelo de eficacia publicitaria en tal red social, mediante el estudio de las características de mencionadas piezas y de los recursos que empleaban.

Estos datos fueron confirmados por la Coordinadora de Comunicación Online de Mango, Carolina Ribalta (abril 2011), de cuya entrevista se extrajeron dos puntos de interés fundamentales:

- Respecto a la presencia de Mango en Facebook, alegó que habían apostado por ella, por tratarse de una red social que permite dirigirse a los clientes ( $y$ a toda persona interesada por la marca) de una manera dinámica, rápida y eficaz, además de simultáneamente, interactiva. Las posibilidades que ofrece esta red fomentan la bilateralidad de la comunicación que Mango mantiene con sus clientes a través de la plataforma, lo que explica el éxito de la comunidad de Mango en Facebook que cuenta con casi 2 millones de usuarios, mujeres en su mayoría, (Ribalta, abril 2011). Respecto a la interacción Mango-clientes a través de la red, Carolina Ribalta (abril 2011) destaca la inmediatez con la que se produce y la segmentación lingüística y geográfica con la que se lleva a cabo.

- Respecto a los resultados de las acciones llevadas a cabo en Facebook, Ribalta (abril 2011) manifiesta que desde Mango siempre se ha creído que el volumen de trabajo que implica mantener una página de las características que tiene su site en Facebook se ve "ampliamente compensado" (Ribalta, abril 2011).

\section{Discusión: las dificultades que entraña la publicidad en las redes sociales}

La dificultad que suponen las redes sociales para la publicidad y, de forma general para la comunicación, en cierta medida, reside en la complejidad que implica su concepto. Pese a los intentos por ofrecer una definición de red social, lo cierto es que no existe una operativa que pueda aplicarse en conveniencia de todas las investigaciones que han abordado las redes sociales como objeto de estudio. En un intento por acotar el imaginario social de la Red, García García y Gértrudix Barrio elaboran un ejercicio metafórico dirigido a repensar los rasgos de un universo tan complejo (García García y Gértrudix Barrio, 2009: 7-30); entonces, llegan a la conclusión de que "el Mare Nostrum Digital es un espacio de encuentro. Un lugar de sumas, de coincidencias, de simultaneidades" (García García y Gértrudix Barrio, 2009: 27). Este espacio, del que las redes sociales forman parte esencial, es inabarcable, por lo que nunca se podrá trazar su cartografía definitiva (García García y Gértrudix Barrio, 2009: 27). 
Sin embargo, a pesar de una falta de convenio conceptual, las redes sociales se han constituido como un objeto de estudio que ha llamado la atención de múltiples investigadores y profesionales, pero tal y como apuntan Pérez-Latre, Portilla y Sánchez Blanco (2011: 64), la mayoría de tales aportaciones son prácticas y no suelen considerar el impacto que tienen estas plataformas mediáticas en las estrategias comunicativas.

Constituidas como una tendencia esencial en el panorama mediático actual, las redes sociales han contribuido al desarrollo de un nuevo tipo de mercado de contenidos masivamente compartidos (Tapscott y Williams, 2006). La interacción múltiple que facilitan permite la colaboración para producir contenidos entre iguales, lo que lleva a hablar de "la economía de la colaboración" (De Salas Nestares, 2010: 79). Esta difusión masiva está estrechamente vinculada al potencial viral que posibilita ese atributo propio de las redes sociales: su interactividad. Las tecnologías que forman parte de la naturaleza misma de las redes sociales han construido un nuevo sistema relacional que están modificando las relaciones personales (Pérez-Latre, Portilla y Sánchez Blanco, 2011: 66), pero además, también están cambiando intensamente las relaciones entre las marcas anunciantes y sus públicos objetivos.

Estas plataformas virtuales constituyen una oportunidad de impacto publicitario, al poder autosegmentarse por intereses, aficiones, estilos de vida y otras variables (De Salas Nestares, 2010: 82) por lo que emergen como clave para el éxito publicitario en la relación esfuerzo/resultado y, consecuentemente, en su equivalente económica, inversión/impactos (Caldevilla Domínguez, 2010: 37). Ahora bien, esta oportunidad está condicionada por un nuevo marco relacional de tales audiencias (Pérez-Latre, Portilla y Sánchez Blanco, 2011: 69). Si se desea generar una reacción positiva, la marca, a través de los profesionales de la publicidad, deberá buscar, en sus mensajes, la aceptación de ese segmento al que se dirige. La clave de una publicidad eficaz, en este sentido, está en generar un flujo de información, de manera que unos y otros, marcas y usuarios, participen de ese flujo en beneficio de todos, explotando todos los recursos que facilitan las redes sociales.

Por ello, la publicidad en las redes sociales busca la proactividad de los usuarios, que no sólo es atractiva para el usuario de las redes, sino que es muy importante para la marca, pues se conforma como un indicador de recuerdo y, consecuentemente, de notoriedad. Al buscar esta participación implicativa por parte del usuario, la publicidad está utilizando a las redes sociales como una herramienta de contacto directo con el consumidor que puede ser de gran utilidad si se considera que tal contacto directo permite conocer profundamente al consumidor (Pérez-Latre, Portilla y Sánchez Blanco, 2011: 70). En este sentido, las redes sociales se constituyen como valiosas fuentes de información para que las agencias de la publicidad diseñen eficazmente sus estrategias.

En el contexto publicitario actual, la eficacia emerge como una máxima. La medición publicitaria de una campaña permite saber con tiempo su rendimiento en cada una de sus etapas de exposición (Olabarri Fernández y Quintana, 2009: 6). Aunque aún hay dificultades 
para encontrar fórmulas precisas de medición de la eficacia en redes sociales (Pérez-Latre, Portilla y Sánchez Blanco, 2011: 70), existen aportaciones interesantes, como las que proponen Facebook y BrandLift (Gibs y Bruich, abril 2010). Otra aportación interesante es la que ofrecen Baños González y Rodríguez García (2009: 214-238) para valorar el potencial de la eficacia de las campañas publicitarias sociales. Desde una perspectiva próxima, aunque focalizada en otro tipo de publicidad, la propuesta que se plantea en este artículo es también un intento por alcanzar un modelo de eficacia publicitaria en redes sociales.

De un modo u otro, todos estos estudios e intentos determinan la necesidad de generar herramientas capaces de medir la eficacia de estas acciones mediante lo que se ha denominado el Social Media $R O I^{3}$. Tal parámetro mide la eficacia de las acciones comunicativas de una marca que están orientadas a generar reacciones medibles, lo que implica considerar indicadores de diversa naturaleza que se adapten a las peculiaridades de cada estrategia e, incluso, de cada acción. Desde un punto de vista práctico, el Social Media $R O I$ (SMR) es una relación entre el esfuerzo del anunciante y el rendimiento de sus acciones en medios sociales, de forma que su monitorización permitirá calcular el valor en earned media logrado por esas acciones (Influenciador, diciembre 2010b).

\section{Conclusiones.}

Los resultados obtenidos y el análisis teórico realizado previamente, permite extraer una serie de conclusiones de interés.

Aunque la elevada exposición de las marcas en Facebook dificulta el control de todo el discurso que se genera sobre ella y complica la detección de comentarios negativos, tal plataforma se constituye como un instrumento que facilita el desarrollo de estrategias publicitarias eficaces. Marcas como Mango han sabido hacer uso de tales herramientas, logrando generar un discurso positivo y consiguiendo, así, un alto nivel de eficacia.

Los resultados constatan que las redes sociales son un medio adaptado a las peculiaridades del receptor activo y participativo de hoy. Los seguidores de las marcas en las redes sociales sienten la necesidad de participar en la construcción del discurso y la marca debe darles el protagonismo que merecen, demostrando que les escucha. En consecuencia, los formatos que implican al receptor sin obligarlo a participar son los que más éxito tienen en Facebook. La publicidad siempre debe invitar a formar parte del discurso de la marca, debe ofrecer al usuario la posibilidad de ser autor-creador de un discurso corporativo en el que tiene un protagonismo indiscutible, si bien existe una actitud más activa ante formatos que requieren un menor grado de implicación ("me gusta").

\footnotetext{
${ }^{3}$ El Social Media ROI se entiende, más que en términos financieros de retorno de la inversión, en términos de medición del efecto de las acciones comunicativas desarrolladas por un anunciante (Influenciador, diciembre 2010a).
} 
El caso analizado permite perfilar un modelo de pieza publicitaria eficaz en Facebook, caracterizada por una expresión de gran peso visual con una estructura de formato orgánico (específico de Facebook) y cuyo contenido se centra en los beneficios que la marca aporta al usuario.

Este modelo de pieza publicitaria se enmarca en un patrón estratégico de eficacia que facilita un nuevo tipo de Word-Of-Mouth (WOM), con un poder prescriptor próximo al del WOM tradicional, pero con mayor poder viral. Mencionado patrón presenta los siguientes rasgos característicos:

- Cuenta con una oferta de contenidos lo suficientemente interesante para que el público objetivo responda positivamente y lo difunda (viralidad).

- Conforma un punto clave en el cruce de usuarios y contenidos entre los diversos espacios digitales de la marca, al facilitar una convergencia entre ellos.

- Aprovecha con creatividad los recursos y posibilidades que ofrece Facebook para generar engagement.

- Orienta todas las acciones hacia la consecución del posicionamiento estratégico pretendido por la marca dentro de su mercado competitivo para la consecución de una imagen positiva.

El caso concreto estudiado en esta propuesta ha permitido además extraer un modelo eficaz de estrategia publicitaria en Facebook, capaz de orientar la construcción de anuncios efectivos a partir del estudio de experiencias de éxito. En este sentido, esta modesta investigación contribuye a la búsqueda de un modelo capaz de determinar formatos publicitarios rentables en redes sociales. 


\section{REFERENCIAS BIBLIOGRÁFICAS}

Baños GonzÁlez, Miguel y Rodríguez García, Teresa C. (2009): "Desarrollo de un modelo de predicción de la eficacia para la publicidad social", en Revista Icono14, vol. 7, no 2, pp. 214-238.

DOI: http://dx.doi.org/10.7195/ri14.v7i2.324

Boyd, Danah M. y ElLISON, Nicole B. (2008): "Social Network Sites: Definition, History, and Scholarship", en Journal of Computer-Mediated Communication, International Communication Association, vol. 13, no 1, pp. 210-230.

CALDevilla Domínguez, David (2010): "Nuevas lecturas del concepto de publicidad a partir de las TIC", en Questiones Publicitarias, vol. I, no 15, 2010, PP. 35-51. Recuperado (30 de septiembre 2011) de http://www.maecei.es/pdf/n15/articulos/3_Nuevas_lecturas_del_concepto_d e_publicidad_a\%20partir_de_las_TIC.pdf

De SalAs Nestares, Ma Isabel (2010): "La publicidad en las redes sociales. De lo invasivo a lo consentido", en Revista Icono14 [en línea], vol. 8, no 15, pp. 75-84. DOI: http://dx.doi.org/10.7195/ri14.v8i1.281

Fernández HeRmanA, Luis Ángel (2008): "Investigar en tiempo de crisis... y de redes", en Notiweb. Boletín de Weblogs MadrI+D. Recuperado (20 de septiembre 2011)

de http://www.madrimasd.org/informacionIdi/analisis/opinion/opinion.asp?id=3 7289

FloRes Vivar, Jesús Miguel (2009): "Nuevos modelos de comunicación, perfiles y tendencias en las redes sociales", en Comunicar, vol. XVII, n033 (1 de octubre 2009), pp. 73-81. DOI http://dx.doi.org/10.3916/c33-2009-02-007

García García, Francisco y GÉRTRUdix Barrio, Manuel (2009): "El Mare Nostrum Digital: mito, ideología y realidad de un imaginario sociotécnico", en Revista Icono14, vol.7, no 1, pp. 07-30.

DOI: http://dx.doi.org/10.7195/ri14.v7i1.331

GiBS, Jon y BRUICH, Sean (abril 2010): "Nielsen/Facebook Report: The Value of Social Media Ad Impressions", en Nielsenwire. Recuperado (25 de septiembre 2011)

de http://blog.nielsen.com/nielsenwire/online_mobile/nielsenfacebook-adreport/

Gordon, Robert y CuRlee Wanda (2011): "Six Degrees of Separation, Chaos / Complexity Theory, Social Networking and Project Management", en PM World Today, vol. XIII, no III, pp. 1-7. 
IAB SpAin ReSEARCH (noviembre 2010): II Estudio sobre redes sociales en Internet, International Advertising Bureau y Elogia Marketing Singular. Recuperado (25 de septiembre 2011) de http://www.slideshare.net/IAB_Spain/informeredes-sociales-iab-2010-noviembre-2010

INFLUENCIADOR (diciembre 2010b): "Práctica del Social Media ROI", en Influenciador.net. Recuperado (25 de septiembre 2011) de http://www.influenciador.net/influenciador/calcular-socia-media-roi/

INFLUENCIADOR, (diciembre 2010a): "Teoría del Social Media ROI", en Influenciador.net. Recuperado (25 de septiembre 2011) de http://www.influenciador.net/influenciador/social-media-roi/

InSITES Consulting (2010): Social Media around the world, InSites Consulting 2010 Edition.

Olabarri Fernández, Elena y Quintana, Miguel Angel (2009): "Eficacia de las campañas publicitarias: El caso de las campañas de turismo del Gobierno Vasco", en Questiones Publicitarias, vol. I, no 14, PP. 1-19. Recuperado (30 de septiembre 2011) de http://www.maecei.es/pdf/n14/articulos/A1_Eficacia_de_las_campanas_publ icitarias_el_caso_de_las_campanas_de_turismo_del_Gobierno_Vasco.pdf

Pérez-Latre, Francisco Javier, Portilla, Idoia y SÁnchez Blanco, Cristina (2011): "Social Networks, Media and Audiences: A Literature Review", en Comunicación y Sociedad, vol. XXIV, no 1, pp. 63-74. Recuperado (30 de septiembre 2011) de http://www.unav.es/fcom/comunicacionysociedad/es/resumen.php?art_id=3 78

Qualman, Erik (2011): "21 Social Media Predictions and Trends for 2011", ClickZ [en línea] (5 de enero 2011). Recuperado (25 de septiembre 2011) de http://www.clickz.com/clickz/column/1934793/21-social-media-predictionstrends-

Stelzner, Michael A. (marzo 2009): "Social Media Marketing Industry Report. How Marketers Are Using Social Media to Grow their Businesses", en WhitePaperSource.com. Recuperado (25 de septiembre 2011) de http://marketingwhitepapers.s3.amazonaws.com/smss09/SocialMediaMarket ingIndustryReport.pdf

TAPSCOTT, Don y WiLliAMS, Anthony D. (2006): Wikinomics: How Mass Collaboration Changes Everything, New York, Portfolio.

THE COCKTAIL ANAlysis (noviembre 2008): Informe de resultados. Observatorio de Redes Sociales, $1^{a}$ Oleada, Observatorio de Redes Sociales [The Cocktail Analysis], Madrid. 
The CockTAil Analysis (enero 2010): Informe de resultados. Observatorio de Redes Sociales, $2^{a}$ Oleada, Observatorio de Redes Sociales [The Cocktail Analysis], Madrid.

The CockTAil AnAlysis (febrero 2011): Informe de resultados. Observatorio de Redes Sociales, $3^{a}$ Oleada, Observatorio de Redes Sociales [The Cocktail Analysis], Madrid.

TORRES, Cristina (2010): "Emotion Ranking, la estrategia de Mango en Redes Sociales", en Redessociales. Recuperado (25 de septiembre 2011) de http://www.redessociales.es/2010/12/22/emotion-ranking-la-estrategia-demango-en-redes-sociales/

Vincosblog [Base de Datos: Alexa y Google Trends] (diciembre 2010): "World Map of Social Networks", en Vincosblog. Recuperado (25 de septiembre 2011) de http://www.vincos.it/world-map-of-social-networks/

Recursos de análisis y fuentes primarias

MANGo (2011): "Site oficial de Mango en Facebook", en Facebook [en línea] (marzoabril 2011), recuperado (26 de septiembre 2011) de http://www.facebook.com/mango.com

MANGo (2011): "Site oficial de Mango", en Mango [en línea] (febrero-abril 2011), recuperado (26 de septiembre 2011) de http://www.mango.com

RIBALTA, Carolina (2011): Entrevista de elaboración propia (abril 2011), Madrid.

[Recibido: 28 de marzo de 2012. Aceptado: 9 de septiembre de 2013]. 